\title{
Quantification of the concentration and deposition of atmospheric black carbon to natural surfaces
}

\author{
Pratima Gupta $^{1}$, Ashok Jangid ${ }^{2}$ and Ranjit Kumar ${ }^{1}$ \\ ${ }^{1}$ Department of Chemistry, ${ }^{2}$ Department of Physics and \\ Computer Science, Faculty of Science \\ Dayalbagh Educational Institute (Deemed University), \\ Dayalbagh, Agra-5 (India) \\ Email: rkschem@rediffmail.com
}

Black carbon is complex of light-absorbing mixture and emitted directly into the atmosphere and falls into the smallest categories of fine particles $\left(\mathrm{PM}_{2.5}\right)$. It gets released into the atmosphere from various sources, transported great distances down wind, finally settled to the earth surfaces via wet and dry deposition and impact air quality both locally and intercontinentally. $\mathrm{BC}$ is an ideal tracer for particle deposition because it is nonvolatile and effectively chemically inert, although it becomes internally mixed with other aerosol species in the atmosphere. Thus, measurements of $\mathrm{BC}$ deposition are not only essential for constraining BC sinks and atmospheric lifetime but also useful for investigating aerosol deposition more broadly. Therefore, this study deals with the quantifying the mass concentration of black carbon and their deposition on foliar surfaces in Agra over IndoGangetic basin. BC concentration is $7.3 \mu \mathrm{g} \mathrm{m}^{-3}$ and ranged from 0.1 to $75.6 \mu \mathrm{g} \mathrm{m}^{-3}$ while deposition flux of black carbon is $1.2 \mathrm{mg} \mathrm{m}^{-2} \mathrm{~d}^{-1}$ and ranged from 0.01 to $11.8 \mathrm{mg} \mathrm{m}^{-2} \mathrm{~d}^{-1}$. Study highlights high variation in $\mathrm{BC}$ in day/night and season-season may be due to variation in source strength as well as meteorological conditions and long range transport. The higher concentration of dry deposition flux may be due to the high load of black carbon concentration in winter season. The lowest black carbon concentration in the monsoon season may be due to the low source strength and strong winds which lead for dispersion of particles. The theoretical derived and experimentally determined dry deposition flux of BC is in the reported range. 